\title{
Analysis and Reflection on the Effect of Population Fertility Policy in China
}

\author{
Liying Yin \\ Jilin Agricultural University, Changchun 130118, China \\ ylyjlnd@126.com
}

Keywords: Population fertility policy, implementation effect, adjustment, way.

\begin{abstract}
The implementation of population fertility policy in our country has both positive effects and existing problems. Guided by the Marxist theory of population, And to combine the literature research and investigation, from the development of productive forces to meet the needs of a large number of people, tackling the problem to address the imbalance in the birth sex ratio, the implementation of "comprehensive two children" to alleviate the aging of the population and other aspects. Actively exploring the effective ways of adjusting population fertility policy in China.
\end{abstract}

\section{The positive effect of population fertility policy in China}

Since the beginning in the seventh decade of last century of our family planning policy, and in March 1978 to the legal form of our Constitution. At this point, significant progress has been made in population development.

Table 1: The Population and Birth and Natural Growth Rate of China in 2000-2015

\begin{tabular}{|c|c|c|c|c|c|}
\hline Years & $\begin{array}{c}\text { Number of } \\
\text { births } \\
\text { (million) }\end{array}$ & $\begin{array}{c}\text { Population birth } \\
\text { rate } \\
(\%)\end{array}$ & $\begin{array}{c}\text { Population } \\
\text { mortality rate } \\
(\%)\end{array}$ & $\begin{array}{c}\text { Natural } \\
\text { population } \\
\text { growth rate (\%) }\end{array}$ & $\begin{array}{c}\text { Total } \\
\text { population } \\
\text { (million) }\end{array}$ \\
\hline 2000 & 1776 & 14.03 & 6.45 & 7.58 & 126583 \\
2001 & 1708 & 13.38 & 6.43 & 6.95 & 127627 \\
2005 & 1617 & 12.40 & 6.51 & 5.89 & 130756131448 \\
2006 & 1584 & 12.09 & 6.81 & 5.28 & 132129 \\
2007 & 1594 & 12.10 & 6.93 & 5.17 & 132802 \\
2008 & 1608 & 12.14 & 7.06 & 5.08 & 133474 \\
2009 & 1615 & 11.95 & 7.08 & 4.87 & 133972 \\
2010 & 1574 & 11.90 & 7.11 & 4.79 & 134735 \\
2011 & 1604 & 11.93 & 7.14 & 4.79 & 135404 \\
2012 & 1635 & 12.10 & 7.15 & 4.95 & 136072 \\
2013 & 1640 & 12.08 & 7.16 & 4.92 & 136782 \\
2014 & 1687 & 12.37 & 7.16 & 5.21 & 137462 \\
2015 & 1655 & 12.07 & 7.11 & 4.96 & \\
\hline
\end{tabular}

Data sources: China Population and Employment Statistics Yearbook

\subsection{The population growth rate has been effectively controlled}

After a sharp decline in the 1970s and a slow decline in the 1980s, the population of China reached the low fertility level by the end of the 20th century, and the fertility rate was changed. Although the absolute number of our population (except for a few years) has been increasing, the rate of population growth has slowed down. Excluding the impact of natural disasters for three years, making the 1960s, 1961s, population of China growth in negative growth, compare the average growth rate of the population of China, in 50s the average growth of $19.9 \%$, in 60 s the average growth of $23.4 \%$, in 70 s the average growth of $14.8 \%$, in 80 s the average growth of $13.4 \%$, in 90 s the average growth of $9.1 \%$,by the 21 st century, 2001 to 2010 the average growth rate dropped to $5.7 \%$.It can be seen from China Population and Employment Statistics Yearbook, the birth rate of China is $33.4 \%$ in 1970 
dropped to $12.07 \%$ in 2015 ,the natural population growth rate is $25.8 \%$ in 1970 dropped to $4.96 \%$ in 2015 , is half of the world average.

\subsection{The quality of the population has been greatly improved}

National physical fitness has been strengthened, since the founding of the people's Republic of China, especially in the past 30 years of reform and opening up, the improvement of national physical fitness has made remarkable achievements. From the two basic indicators of the physical quality of the population - infant mortality and life expectancy at birth, the rate of descent is very fast, Our infant mortality rate from 200 per thousand in 1940s, declined to 13 per thousand in 2010,life expectancy rose from 40 in 1940s to just under the age of 72.5 in 2010.This shows that due to social and economic development, improvement of medical conditions, people's health has improved significantly.

The cultural quality of the population has been steadily improved. Since the founding of the country, especially 30 years of reform and opening up, China's population cultural quality has been significantly improved. According to the data of the average years of education in China's labor force, The education level of the labor force in has been increased, According to the data of average years of education in China, the 1982 labor force average years of schooling is 4.21 years, to 2014 increased to 9.28 years, China's education level of labor population continues to improve, and create conditions for the transition from a large population to the talent.

\section{Problems in the implementation of China's population fertility policy}

\subsection{Raise in total population}

It can be seen from Table 1, the total population of China's mainland has increased year by year, by the end of 2015(Excluding Hong Kong, Macao SAR and Taiwan Province, as well as the number of overseas Chinese) has reached 137462 million people, increase of 6.8 million compared to the end of 2014. The birth population was 1655 million, the birth rate was $12.07 \%$, the population mortality rate was $7.11 \%$, the natural population growth rate was $4.96 \%$, year-on-year decrease $0.25 \%$ o than last year.

\subsection{Birth population sex ratio increased}

According to international practice, the normal level of the sex ratio at birth should be maintained between 103-107. Namely, each born 100 girls, corresponding to the birth of the baby boy is 103-107, and has been in China for more than 30 years beyond the indicators, starting around 1982, the sex ratio of birth population reached 107.2, continued to rise, to reach the peak of 121.2 in 2004, individual provinces have long maintained at 130. From 2009 began a sustained decline in 5 years, it is regarded as a turning point in China's sex ratio at birth, however, according to the data released by the National Bureau of Statistics, the sex ratio at birth was 119. 45 and 117. 6 in 2013. The five-year decline was not significant, only 1.85 . In 2015, the male population is 704.14 million and the female population is 670.48 million. the sex ratio of the total population is 105.02 and the sex ratio of the born population is 113.51.China is faced with a serious situation of imbalance between men and women.

\subsection{The degree of population aging increases}

According to international practice, the percentage of the population over the age of 60 to $10 \%$, the proportion of the population over the age of 65 to the total population reached $7 \%$ as the national or regional standards into the aging society.

It can be seen from Table 2, starting in 2001, the proportion of the population over the age of 60 to the total population has reached to $10.33 \%$, and the proportion of the population over the age of the population has reached to the total population of $7.1 \%$, has officially entered the stage of aging population. And the proportion increased year by year, by the end of 2015, China's 60 years of age and older population is 22200 people, accounting for $16.1 \%$ of the total population, 65 years old and above population of 14386 people, accounting for $10.5 \%$. of the total population in China has become the world's most populous country in the elderly, but also the population aging is one of the most development speed fast state. 
Table 2: 60 years of age and over, 65 years of age and above the population, the total population ratio

\begin{tabular}{|c|c|c|c|c|}
\hline Years & $\begin{array}{c}\text { 60 years old and } \\
\text { above population } \\
\text { (million) }\end{array}$ & $\begin{array}{c}\text { Ratio of total } \\
\text { population }(\%)\end{array}$ & $\begin{array}{c}\text { 65 years old and } \\
\text { above population } \\
\text { (million) }\end{array}$ & $\begin{array}{c}\text { Ratio of total } \\
\text { population (\%) }\end{array}$ \\
\hline 2000 & 12911 & 10.2 & 8810 & 6.96 \\
2001 & 13183 & 10.33 & 9062 & 7.1 \\
2005 & 14383 & 11 & 10055 & 7.7 \\
2008 & 16985 & 12.79 & 10956 & 8.3 \\
2010 & 17765 & 13.26 & 11883 & 8.9 \\
2011 & 18499 & 13.7 & 12288 & 9.1 \\
2012 & 19362 & 14.3 & 12714 & 9.4 \\
2013 & 20243 & 14.9 & 13161 & 9.7 \\
2014 & 21242 & 15.5 & 13755 & 10.1 \\
2015 & 22200 & 16.1 & 14386 & 10.5 \\
\hline
\end{tabular}

Data sources: China Population and Employment Statistics Yearbook

\section{The way to adjust the fertility policy in China}

\subsection{Develop productivity to meet the needs of many people}

China is the most populous country in the world and the largest developing country in the world, according to the theory of "two kinds of production" of Marx's theory of "the development of human self production and the development of material production", we must vigorously develop the productive forces and develop the economy so as to achieve a virtuous cycle of population reproduction. The working population must be combined with the elements of the material to become the reality of the productive forces, in order to meet the material and cultural needs of the people, and can be in an invincible position in the fierce international competition. People's needs with the development of productive forces and the growth is the embodiment of social progress, however, if the needs of people and social production development is not coordinated, it will affect the stability and development of society. Since the reform and opening up, China's productivity level has been greatly improved, but at present, the main contradiction between the relatively backward social production and the people's growing material and cultural needs is still a major factor restricting the healthy development of China's population. Therefore, we must vigorously develop social productive forces, promote economic stability and rapid development, in order to meet the needs of a large number of people's material and cultural life.

\subsection{To control the imbalance of sex ratio at birth}

The sex ratio of birth population continues to increase, has violated the gender balance of natural law, to the long-term development of China's population, women's status and social stability have serious adverse consequences, need to be resolved as soon as possible. Lead to sex ratio at birth is the direct cause of sustained increase of illegal fetal sex identification for non-medical needs and illegal sex selective termination of pregnancy behavior exists, but its root is the traditional fertility culture strong preference for boys. Therefore, solving the problem of the increasing of population sex ratio at birth, it is necessary to treat the symptoms. "Permanent cure" move, is to establish at all levels of government, and improve the interests of girls and family oriented mechanism and social security system, to lift the daughter family to worry about the family; and to carry out various forms of publicity and education activities to help the masses to establish a "boys and girls are the same" concept of fertility, and then change the boy's cultural preferences, "The standard" of the measures, is to improve the responsibility of the main system, increase the management according to law, the use of laws, administrative regulations, local laws and regulations control, blocking the illegal identification of medical institutions and selective termination of pregnancy supply of technology; 
increase the intensity of law enforcement, through public opinion should be clear, make secret inquiries, the masses reported that the "two non" behavior clues, according to the law to crack down on the comprehensive management of sex at birth to create a good external environment.

\subsection{The implementation of "comprehensive two children" to alleviate the ageing of the population}

In 2015, the eighteenth fifth plenary session of the party Clearly put forward "adhere to the basic national policy of family planning, improve the population development strategy, the full implementation of a couple can give birth to two children's policies, and actively carry out the response to population aging", implementation of the policy of " The universal two-child policy ", to adjust the population structure, social labor supply, based on stabilizing the low fertility level, effectively promote social harmony and sustainable development, in the contemporary era, will benefit future generations. By reducing the cost of child care or financial subsidies, etc., to reduce the economic burden of family child care, by extending the maternity leave by the government to pay the way to effectively protect the rights of professional mothers to encourage parenting " The universal two-child policy "; the government should increase the investment of human resources, actively coordinate and integrate social resources, encourage and guide social forces to participate in public education services in an orderly manner, improve the conditions of pre-school education, solve the practical problems of entrustment, entry and enrollment, and meet the needs of urban and rural families Different levels of demand.

\section{Summary}

Population as the main body of social and economic activities, is always influenced by social factors, including the influence of a country's population policy is very important. Since the founding of our country, several generations of collective leadership from the specific national conditions, using Marx's population theory as a guide, to adapt to the development of the development of human own production must be produced with material, to the all-round development of human being for the purpose , from the "laissez-faire" to "family planning", from "natural fertility" to "eugenics", from "a couple only one child" to "comprehensive two children", from "control population" to "improve population quality ", in the different historical stages to develop a corresponding population fertility policy, the population growth from the blind free development to rational, controlled orbit, has made remarkable achievements, inherited, rich, developed the Marxist theory of population, and Will gradually realize the population and economy, population and environment, population and resources of the coordinated development of China's economic and social sustainable development.

\section{References}

[1]. 2000-2015CHINA POPULATION \& EMPLOYMENT STATISTICS YEARBOOK

[2]. China Labor-force Dynamics Survey: Report 2015

[3]. Information on: http:// baike. sogou. com/ v218940. htm?from Title=\%E4\%BA\% BA\%E5\%8F\% A3\%E8\%80\%81\%E9\%BE\%84\%E5\%8C\%96 